\title{
To study the influence of mercerizing variation on the absorbency and whiteness test for the cotton woven fabrics
}

\begin{abstract}
The mercerization of cotton fabric is common practice in the preparation process that enhances dye uptake and facilitates uniform dyeing in addition to improving dimensional stability, strength, and luster. Changes in microstructure, morphology, and conformation of the cellulose chains also occur during mercerization. The extent of the changes that occur depends on the processing time, caustic concentration, temperature, degree of polymerization. The main objective of this research work is to analyze the whiteness index, absorbency test of the different fabric samples made of different cotton yarns. The count of these yarns was as under $32 \mathrm{Ne}, 35 \mathrm{Ne}, 40 \mathrm{Ne}, 45 \mathrm{Ne}, 50$. These fabrics were treated at different temperatures of $2030,40,50,65^{\circ} \mathrm{C}$. It was found that mercerized cotton fabrics at low-temperature Mercerize is done only on the surface of the fabric but as the temperature is increased the mercerization \& done on the core of the fabric. Absorbency is increased as the temperature is increased. Whiteness index is decreased as the temperature is increased.
\end{abstract}

Keywords: cotton woven fabrics, whiteness index, absorbency test
Volume 6 Issue 2 - 2020

\author{
Ramratan,' Anupam Kumar,' Rohit Kumar ${ }^{3}$ \\ 'Assistant Professor, Department of Textile Engineering, Giani \\ Zail Singh Campus College of Engineering and Technology, \\ Maharaja Ranjit Singh Punjab Technical University, India \\ 2Professor, Department of Textile Engineering, Giani Zail Singh \\ Campus College of Engineering and Technology, Maharaja Ranjit \\ Singh Punjab Technical University, India \\ ${ }^{3}$ Research Scholar, Department of Textile Engineering, Giani Zail \\ Singh Campus College of Engineering and Technology, Maharaja \\ Ranjit Singh Punjab Technical University, India
}

\begin{abstract}
Correspondence: Ramratan, Department of Textile Engineering, Giani Zail Singh Campus College of Engineering and Technology, Maharaja Ranjit Singh Punjab Technical University, Bathinda-151001, Punjab, India,

Email ramratan333@gmail.com, anup28298@yahoo.com
\end{abstract}

Received: March 21, 2020 | Published: April 21, 2020

\section{Introduction}

Various mechanical and chemical treatments that are routinely applied when processing cotton fibers are very important because they alter fabric performance properties. Among various chemical treatments, mercerization is one of the novels processing that helps to improve the fabric properties. Certain desirable properties such as improved dye uptake, improved luster and improved tensile strength can be imparted to cotton substrate through mercerization. The role of pretreatments such as scouring and bleaching is to improve the absorbency and whiteness of cotton by removing the naturally occurring impurities, including colored matter i.e. pigments. ${ }^{1}$ Essentially it is carried out by treating cotton material with a strong solution of caustic soda $\left(52^{\circ} \mathrm{Tw}\right)$ at lower temperatures. As a result, mercerization takes place and material acquires the desired properties of luster, increased strength and dye uptake. When treated in a strong solution of $\mathrm{NaOH}$ cotton fibers swell laterally and shrink longitudinally causing interesting and important changes in the properties of yarns or fabrics made from them. ${ }^{2}$ The reaction between the cellulose fiber and the alkaline solution is an exothermic reaction, and any increase in the treatment temperature reduces the absorption of the alkali, thus reducing the effectiveness of the mercerization. The studied treatment of cotton yarn with a wide range of alkaline concentrations and processing temperatures. He divided the results into the three divisions viz, complete mercerization, partial mercerization and un-mercerized and demonstrated with the help of a chart showing the relationship between the alkaline concentration and the temperature Sisson. ${ }^{3,4}$ The treatment of cotton yarns includes singing to remove the protruding fibers, mercerization to give better dimensional stability, increased luster, increased dye and finishing chemical uptake, better mechanical properties and smoothness, scouring to remove non-cellulosic impurities and oxidative bleaching to destroy natural coloring matter for white program or dyeing. ${ }^{5,6}$ Cotton fibers are subjected at different temperatures during growing, wet pretreatments, laundering and ironing, which alter their properties. Elevated temperature of drying has altered cotton fiber properties, such as length, strength, elongation and spinning performances, as well as surface components and internal porous system. ${ }^{7}$ Mercerization is used to improve such properties as dye affinity, chemical reactivity, dimensional stability, tensile strength, luster and smoothness. ${ }^{8}$ The treatment is normally applied either to yarn or to fabric itself in either slack state to obtain stretch properties or under tension to improve such properties of strength and luster. Generally caustic concentration in the range of $48-54^{\circ} \mathrm{T}$. Although if improved dye affinity is the objective, $30-5^{\circ} \mathrm{Tw}$ can be used. A contact time of 30 seconds can be used. A penetrate is essential if the fabric is in the grey state to permit wetting. Generally, cresols or organic phosphates $(0.5-1 \%)$ along with Noahcan be used for pre wetting. ${ }^{9}$ Temperature usually is kept at $15-17 \mathrm{C}$, But Increase in mercerization temperature has been found in improving properties of the fabric. ${ }^{10}$ Here the objective of the study is to study the effect of mercerizing temperature on the properties of the cotton fabrics.

\section{Materials and methods}

\section{Materials}

Sample preparation: This research work I have used different fabric samples made of different count cotton yarns. I have used cotton plain woven fabrics different count in $32 \mathrm{Ne}, 35 \mathrm{Ne}, 40 \mathrm{Ne}, 45 \mathrm{Ne}$, $50 \mathrm{Ne}$. These fabrics were treated at different temperatures of 20 $30,40,50,65^{\circ} \mathrm{C}$. According to my research work in the laboratory was maintained temperature. It has been treated cotton samples with caustic soda $(\mathrm{NaOH})$ at different temperature range $2030,40,50$, $65^{\circ} \mathrm{C}$. We have checked the effect on the properties of cotton woven fabrics. we have done the work on the pad steamer machine in the lab 
in for this purpose we set the temperature of the steamer for this the strength of the caustic soda is $300 \mathrm{gpl}$ has taken as the standard of the company after treating with different temperature.

Bleaching for cotton fabrics: The bleaching operations of the samples were done in a Mathis Labomat lab dyeing machine.Fabrics were treated according to a set of values for Hydrogen peroxide concentration (1.6-2.3g/L), Different temperature and time (20min). Sample weight was 13.4 gconstant with a 1:10 Material liquor ratio (MLR). Concentrations of $\mathrm{NaOH}$ and Kappazon $\mathrm{H} 53$ were kept 2 and $1 \mathrm{~g} / \mathrm{L}$ constant respectively in each bleaching bath. The treatment of the fabric samples has done as per shown in Figure 1 \& Figure 2 (Table 1).

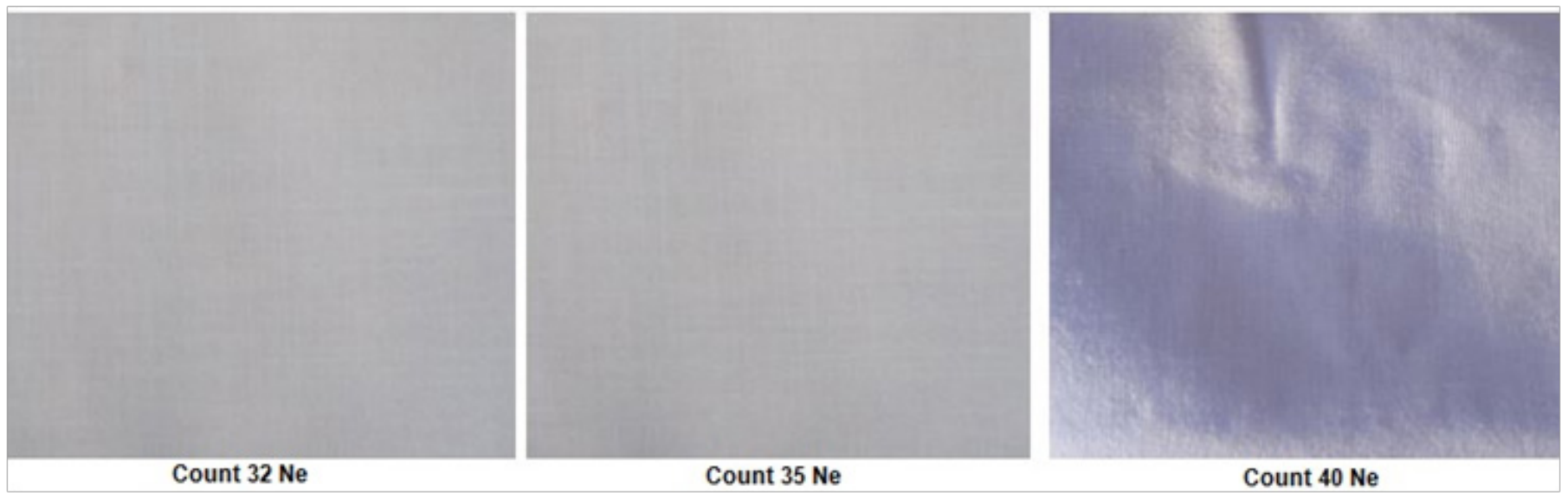

Figure I Cotton fabrics with different count.

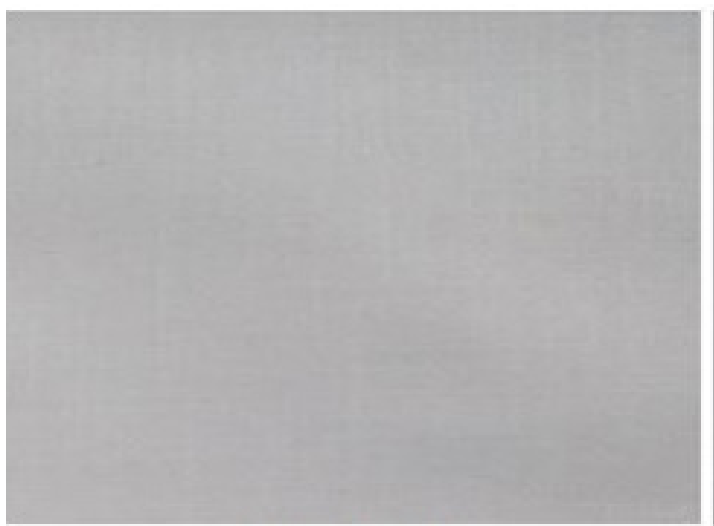

Count $45 \mathrm{Ne}$

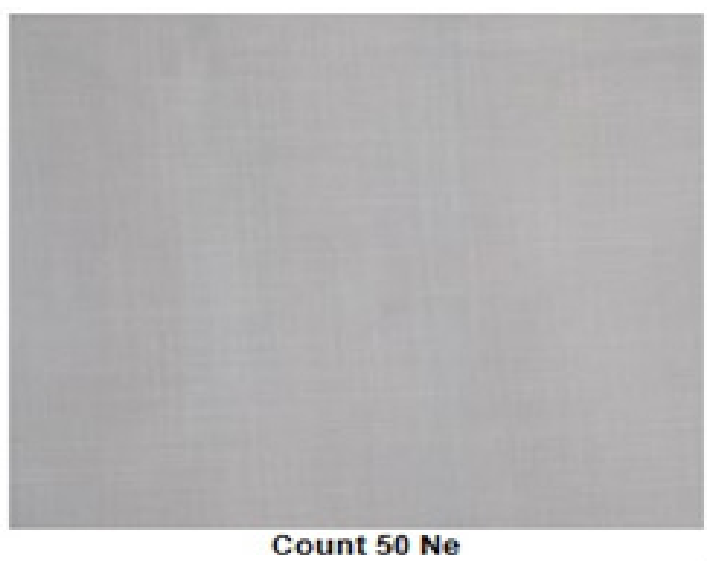

Figure 2 Cotton fabrics with different count.

\section{Methods}

Absorbency test: This test is done to check the efficiency of mercerization.

Method to perform the test: The put a drop of water on the fabric and time is noted in which fabric absorb it with the help of stop watch. Water absorption is used to determine the amount of water absorbed under specified conditions. Factors affecting water absorbent include. Type of plastic, additives used, temperature and length of exposure. The data sheds light on the performance of the material in water or humid environments.

Test procedure: For the water absorption test, the specimens are dried in an oven for a specified time and temperature and then placed in a desiccator to cool. Immediately upon cooling the specimens are weighed. The material is then emerged in water at agreed upon conditions, often $23^{\circ} \mathrm{C}$ for 24 hours or until equilibrium. Specimens are removed, patted dry with a lint free cloth, and weighed.

The strip of $5 \mathrm{~cm}$ from left, middle \& right, in cut out from the from the white specimen after pretreatments and dip in up to level of $1 \mathrm{~cm}$ from down side in dip tester contains solution of tint for $1 \mathrm{~min}$. then rubbered and measured per standard ASTM D-57 (Figure 3).

Whiteness index (WI) test: The beached fabrics were tested in a spectrophotometer (datacolor 650, USA) for determining the whiteness index in D65 illuminant and $10^{\circ}$ observer setting. This test is done on bleached and Mercerized sample to check the whiteness level of the fabrics. It shows whether the fabric has achieved the whiteness according to customer demand or not. This test is done with the help of Portable spectrophotometer or with CCM system (Figure 4). 
Use To check the Whiteness level of the fabric. For this in purpose there are 2 methods to check the whiteness of the fabric. If the fabric is bottom cloth them, we make the 2 layers of sample. But for the shirting fabric we make the 4 layers of the sample. The standard of whiteness in the Nahar is 70CIE unit. For RFD samples, RFD-Ready for dyeing. The pure white which is not dyeing 80CIE unit.

a. CIE stands for complain International of encourage. b. The Readings of the whiteness index is given in table below.

c. Basically, the whiteness is decreasing with the increasing the temperature of fabric

d. Because the NAOH(Caustic) makes a yellowish on the test cotton sample.
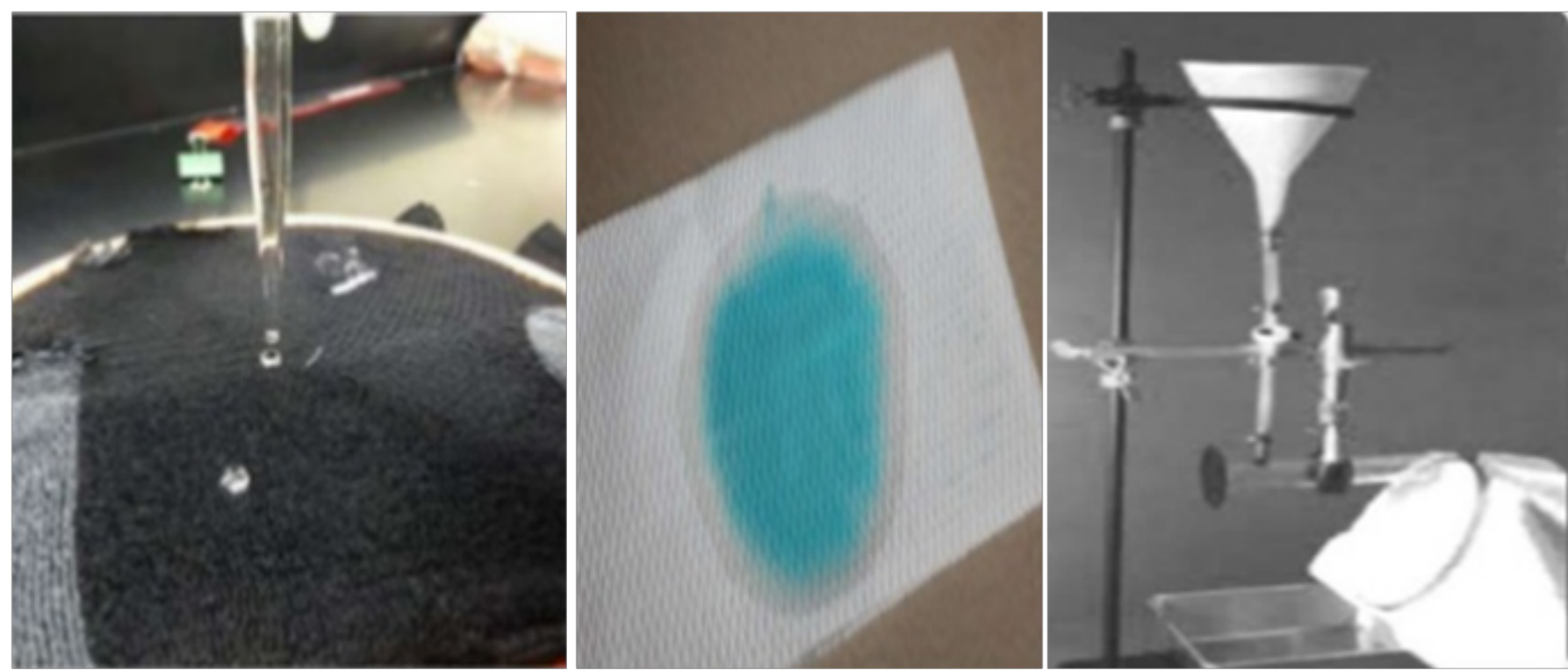

\section{Figure 3 Absorbency tester.}
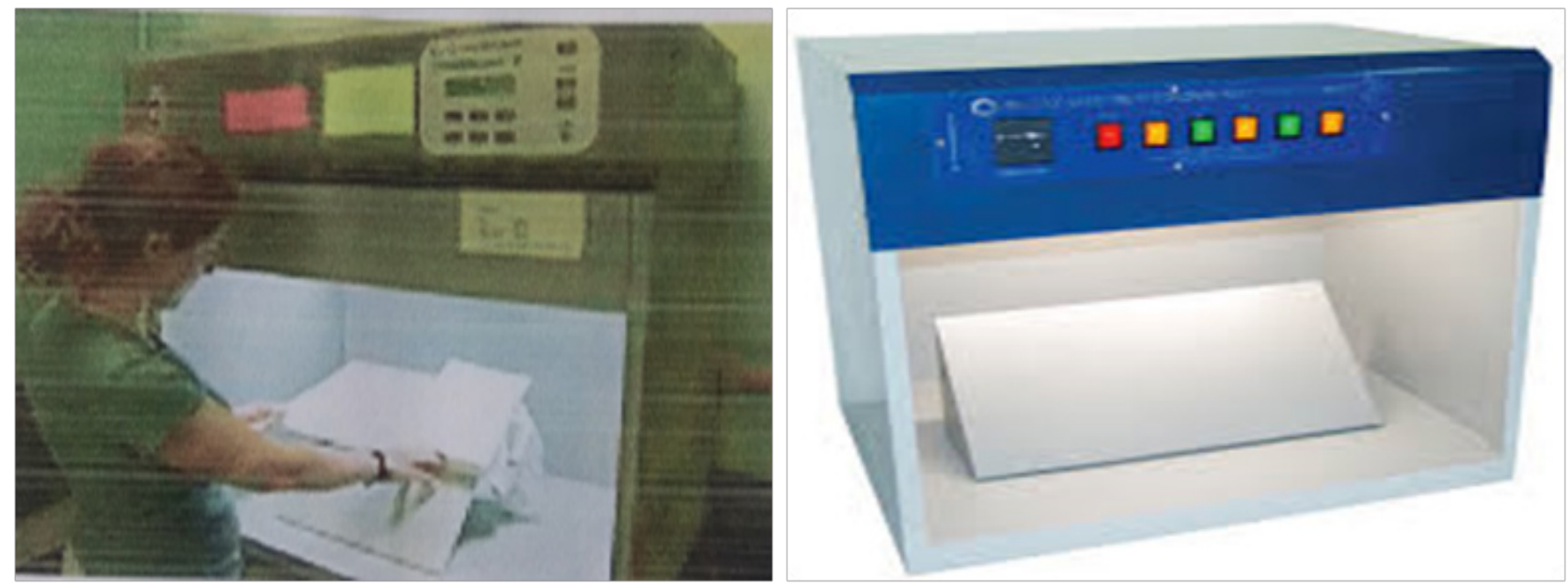

Figure 4 Portable spectrophotometer. 
Table I Experimental plan of the work

\begin{tabular}{|c|c|c|c|}
\hline S.no. & Sample reference & Count $(\mathrm{Ne})$ & Temperature $\left({ }^{\circ} \mathrm{C}\right)$ \\
\hline I & SII & 32 & 20 \\
\hline 2 & $\mathrm{~S} 12$ & 32 & 30 \\
\hline 3 & $\mathrm{SI3}$ & 32 & 40 \\
\hline 4 & $\mathrm{SI} 4$ & 32 & 50 \\
\hline 5 & SI5 & 32 & 65 \\
\hline 6 & S2I & 35 & 20 \\
\hline 7 & S22 & 35 & 30 \\
\hline 8 & S23 & 35 & 40 \\
\hline 9 & S24 & 35 & 50 \\
\hline 10 & S25 & 35 & 65 \\
\hline II & S3I & 40 & 20 \\
\hline 12 & S32 & 40 & 30 \\
\hline 13 & S33 & 40 & 40 \\
\hline 14 & S34 & 40 & 50 \\
\hline 15 & S35 & 40 & 65 \\
\hline 16 & S4I & 45 & 20 \\
\hline 17 & S42 & 45 & 30 \\
\hline 18 & S43 & 45 & 40 \\
\hline 19 & S44 & 45 & 50 \\
\hline 20 & S45 & 45 & 65 \\
\hline 21 & S5I & 50 & 20 \\
\hline 22 & S52 & 50 & 30 \\
\hline 23 & S53 & 50 & 40 \\
\hline 24 & S54 & 50 & 50 \\
\hline 25 & S55 & 50 & 65 \\
\hline
\end{tabular}

\section{Result and discussion}

\section{Absorbency test for the cotton woven fabrics}

We observed result according to the (Tables 2-6 and Figures 5-9) that as the temperature of the $\mathrm{NaOH}$ (caustic) is increased than the absorbency of the fabric is also increase. The course fabric will be absorbed water up take quickly as compare to finer fabric. At the low temperature the mercerization is done on the surface of the fabric, but as the temperature $\left({ }^{\circ} \mathrm{C}\right)$ is increasing then the mercerization done on the core of the fabric. It was observed all figure of the same trend.

Table 2 Effect of temperature on water droplet absorption time $32 \mathrm{Ne}$

\begin{tabular}{ll}
\hline Temperature & Time $(\mathrm{Sec})$ \\
\hline 65 & 2.5 \\
50 & 2.5 \\
40 & 3.5 \\
30 & 4 \\
20 & 4.5 \\
\hline
\end{tabular}

Table 3 Effect of Temperature on water droplet absorption time $35 \mathrm{Ne}$

\begin{tabular}{ll}
\hline Temperature & Time $(\mathrm{Sec})$ \\
\hline 65 & 3.5 \\
50 & 3.5 \\
40 & 4 \\
30 & 4.5 \\
20 & 5
\end{tabular}

Table 4 Effect of Temperature on water droplet absorption time $40 \mathrm{Ne}$

\begin{tabular}{ll}
\hline Temperature & Time $(\mathrm{Sec})$ \\
\hline 65 & 4.5 \\
50 & 4.5 \\
40 & 5.6 \\
30 & 6 \\
20 & 7
\end{tabular}

Table 5 Effect of Temperature on water droplet absorption time $45 \mathrm{Ne}$

\begin{tabular}{ll}
\hline Temperature & Time $(\mathrm{Sec})$ \\
\hline 65 & 5.6 \\
50 & 5.6 \\
40 & 6.7 \\
30 & 7 \\
20 & 8 \\
\hline
\end{tabular}

Table 6 Effect of Temperature on water droplet absorption time $50 \mathrm{Ne}$

\begin{tabular}{ll}
\hline Temperature & Time $(\mathrm{Sec})$ \\
\hline 65 & 5.6 \\
50 & 5.6 \\
40 & 6 \\
30 & 6.7 \\
20 & 7
\end{tabular}

\section{Whiteness index test for the cotton woven fabrics}

We observed result according to the (Tables 7-11 and Figures 1014) in the mercerizing treatment the whiteness of fabric is decreasing that is 1 to $1.5 \mathrm{CIE}$ unit is decreasing in the mercerizing process. The reading in table shows that as the temperature. Of caustic solution is increased the whiteness of fabric is decreased. This is the main reasons that because $\mathrm{NaOH}$ solution makes the yellowish layers on the fabric.

Other thing for presents an outstanding perceptive on the interaction between bleaching process variables and their effects on whiteness index. It was found that though hydrogen peroxide despite of being the key element for bleaching, the other variablestemperature and time has greater influence on whiteness index. Whiteness index increases smoothly with the increase of temperature and time. The rate of increase is initially sharp but slows down later on. It can be concluded that though hydrogen peroxide is the main element for bleaching operation, temperature of the bleaching bath has a very important positive influence on whiteness index which can be improved by increasing time duration. 


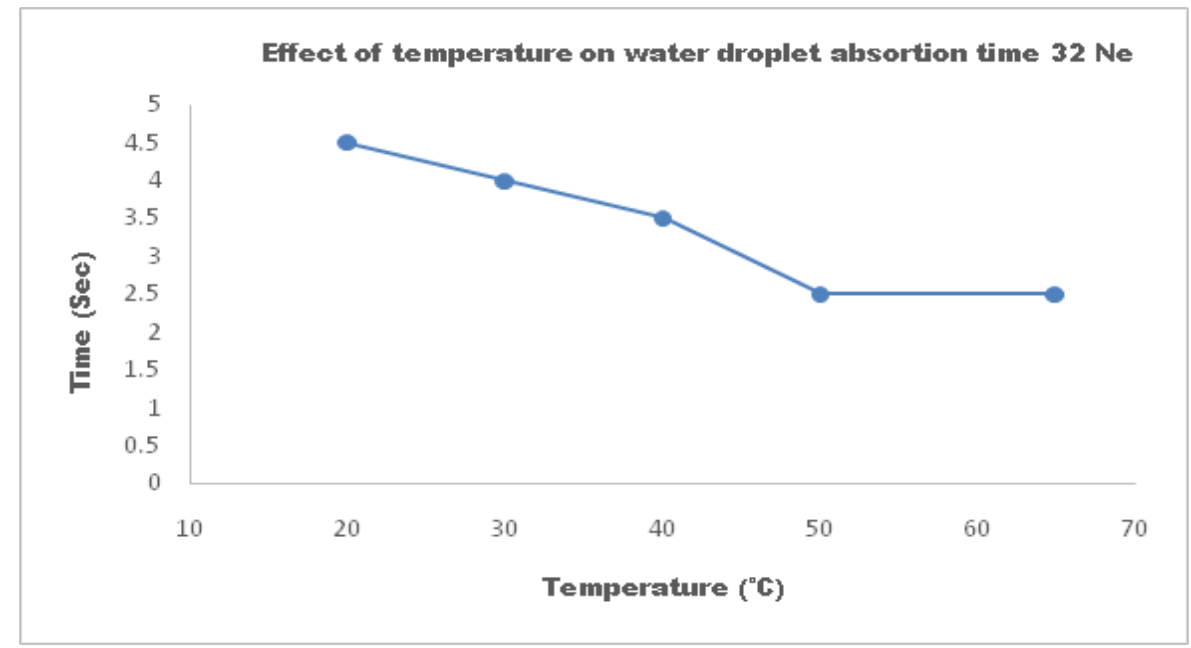

Figure 5 Effect of temperature on water droplet absorption time $32 \mathrm{Ne}$.

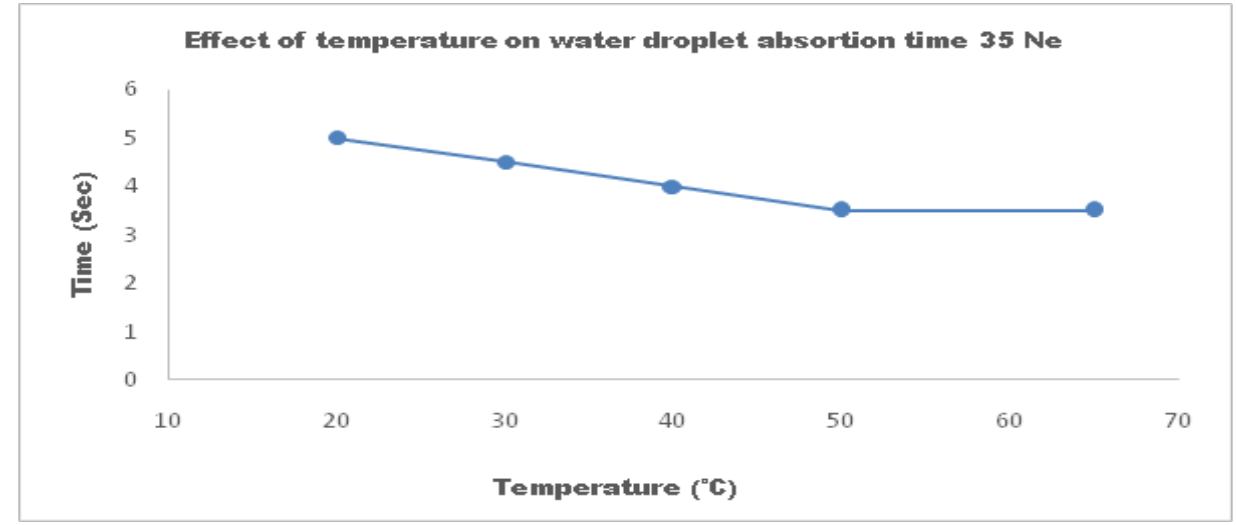

Figure 6 Effect of temperature on water droplet absorption time $35 \mathrm{Ne}$

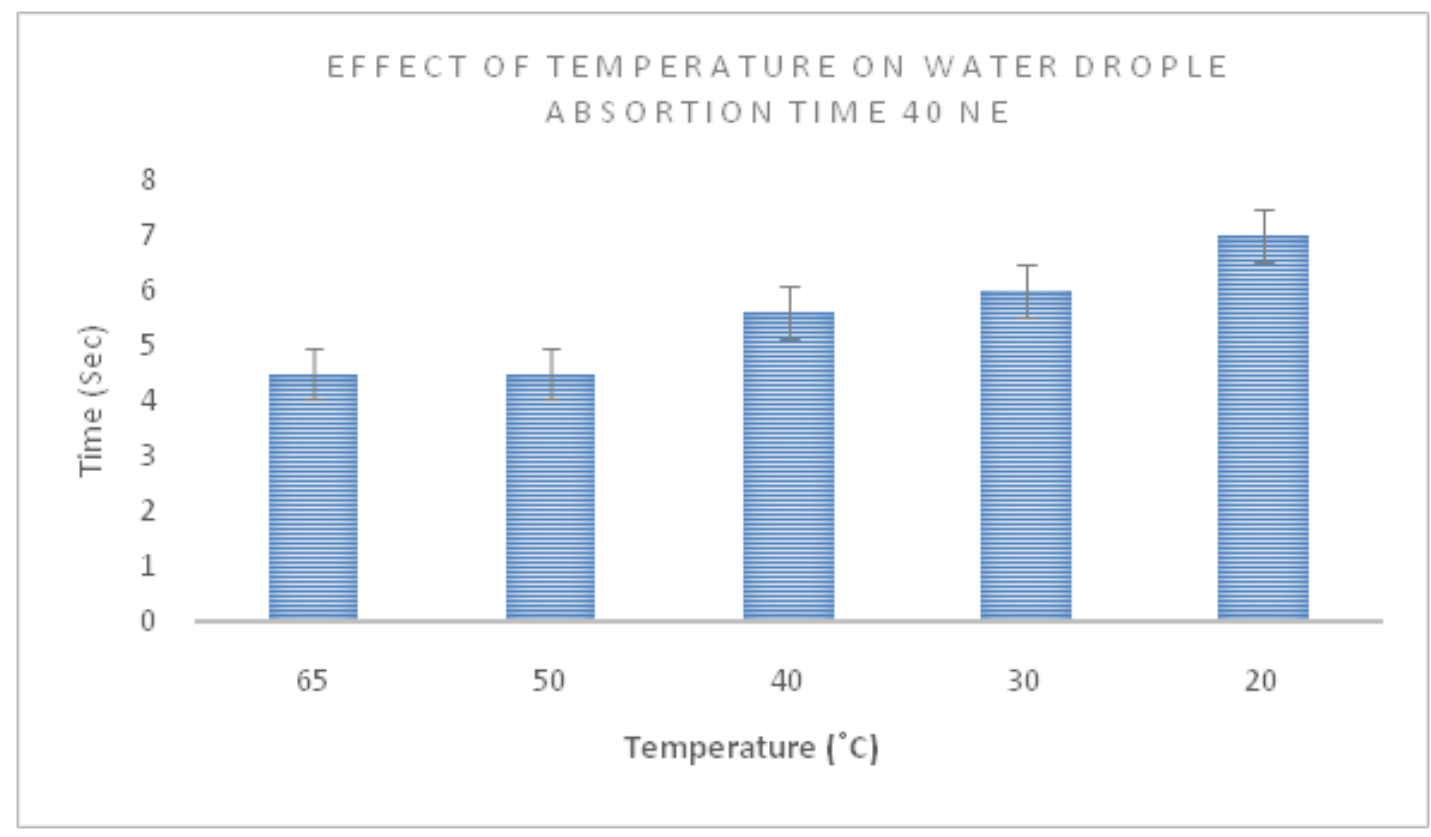

Figure 7 Effect of temperature on water droplet absorption time $40 \mathrm{Ne}$. 


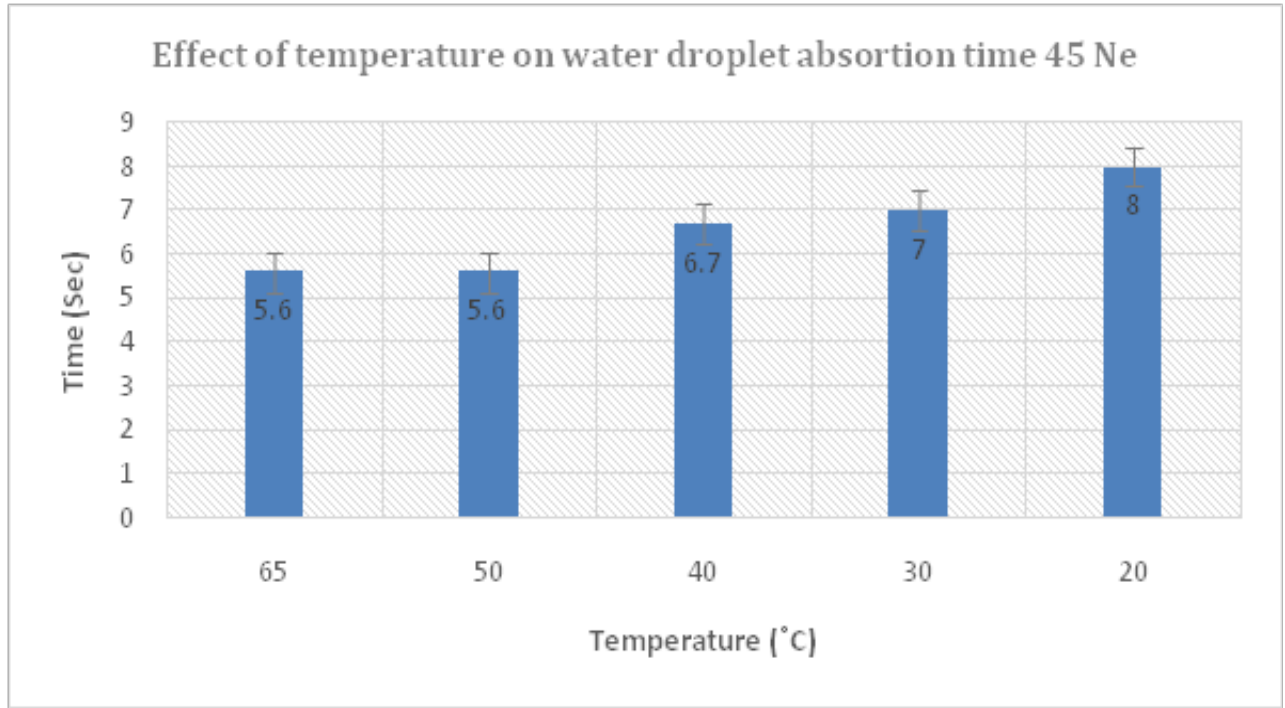

Figure 8 Effect of temperature on water droplet absorption time $45 \mathrm{Ne}$.

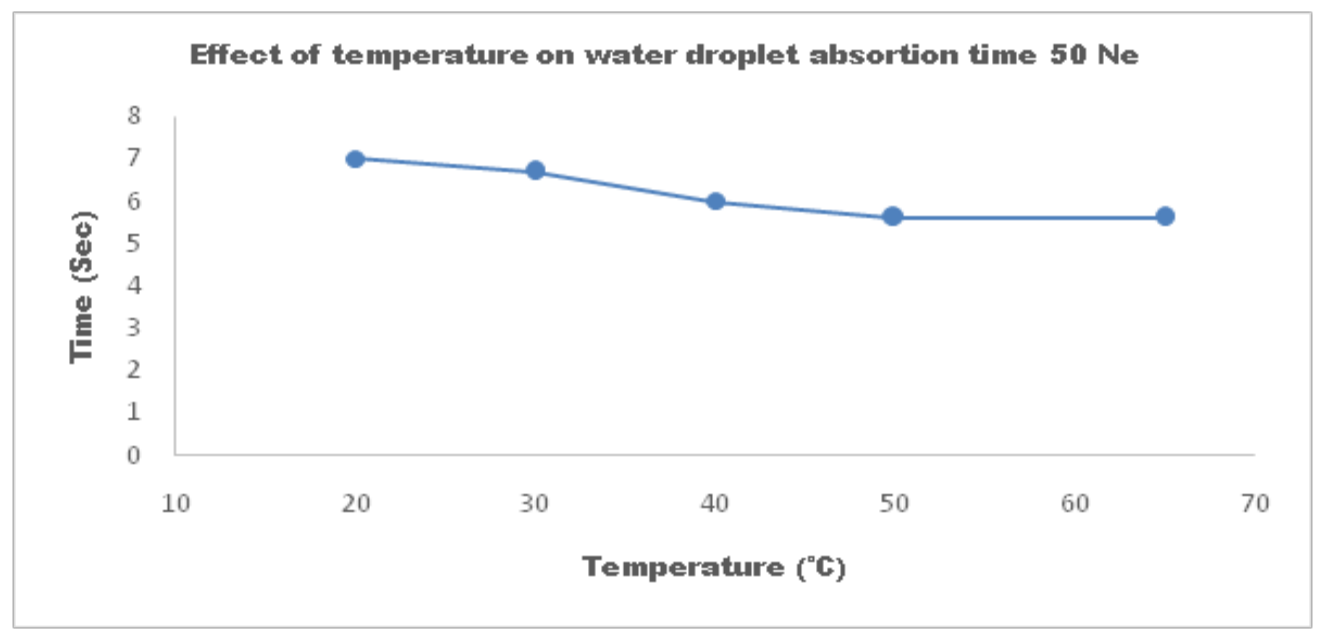

Figure 9 Effect of temperature on water droplet absorption time $50 \mathrm{Ne}$.

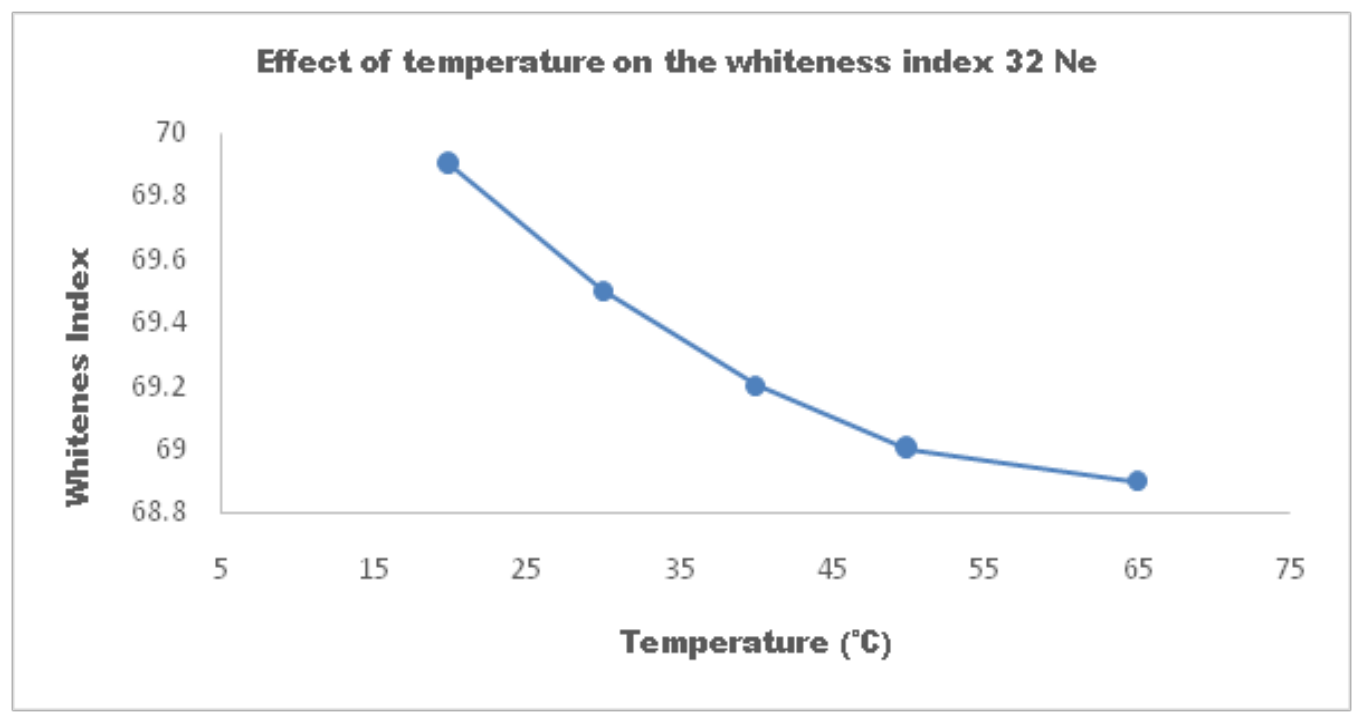

Figure 10 Effect of temperature and whiteness index 32 Neon cotton fabric. 


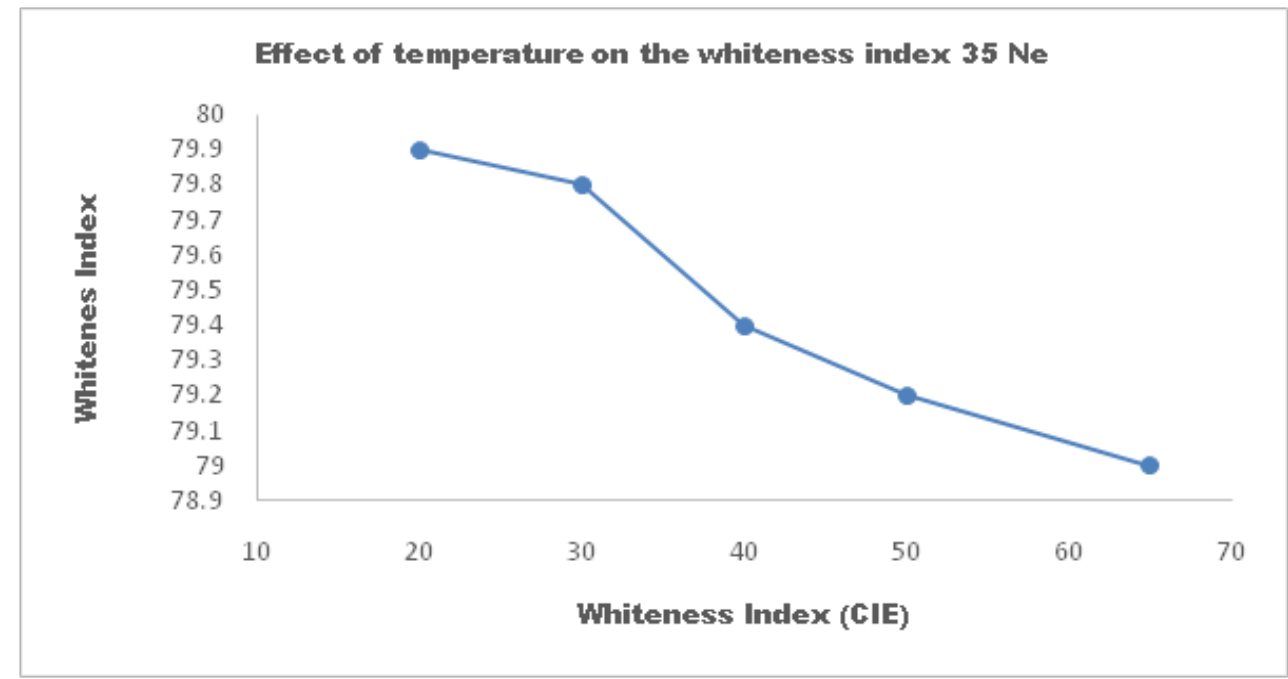

Figure I I Effect of temperature and whiteness index $35 \mathrm{Ne}$ on cotton fabric.

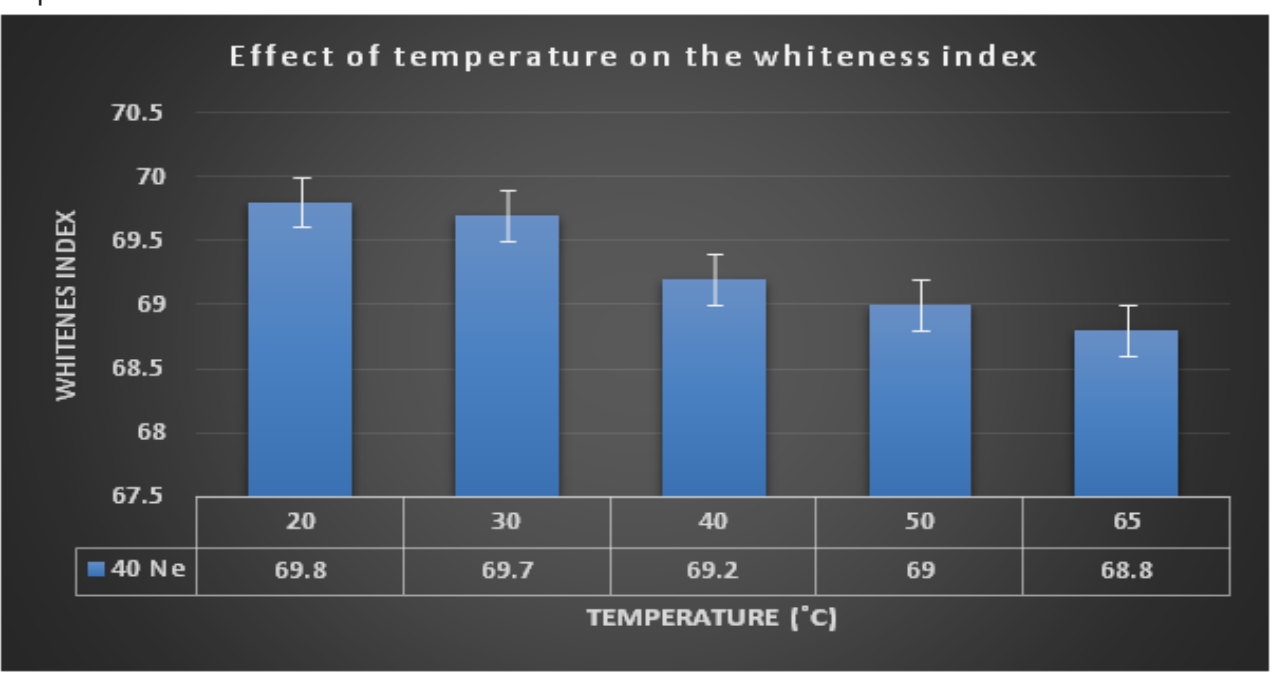

Figure 12 Effect of temperature and whiteness index $40 \mathrm{Ne}$ on cotton fabric.

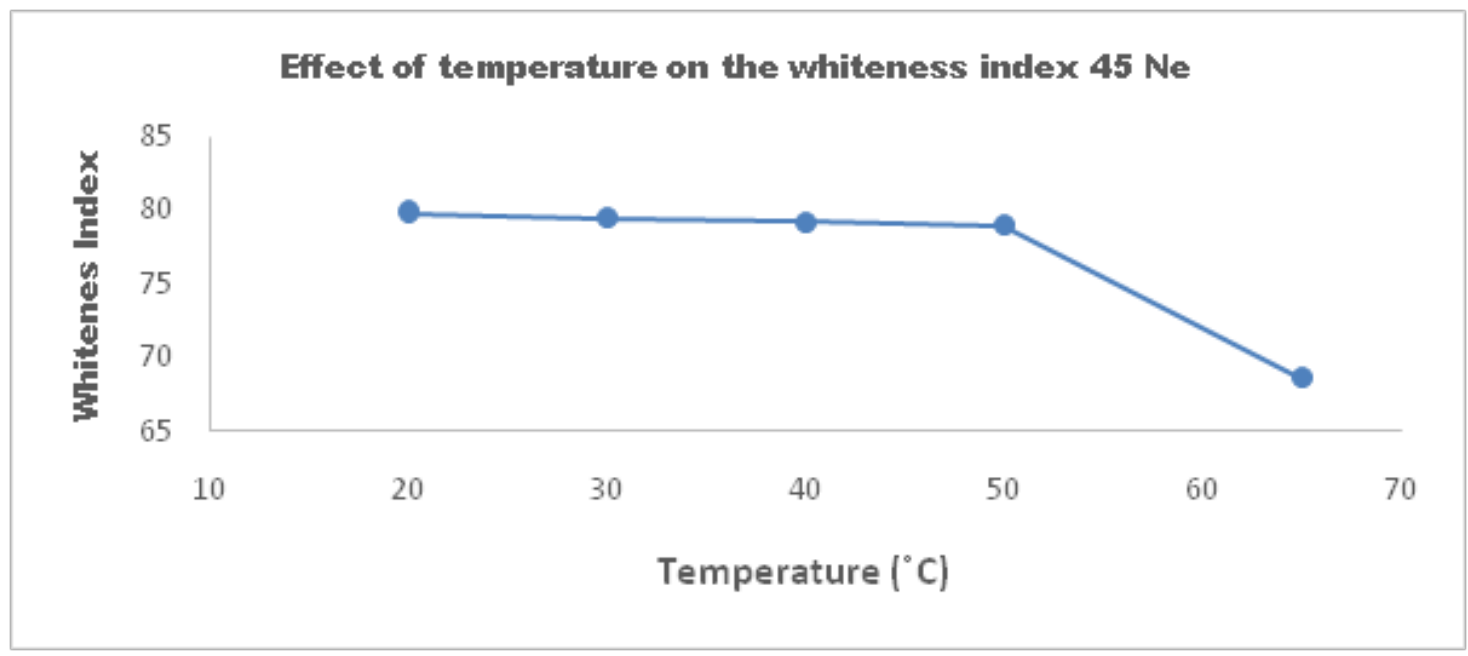

Figure 13 Effect of temperature and whiteness index $45 \mathrm{Ne}$ on cotton fabric. 


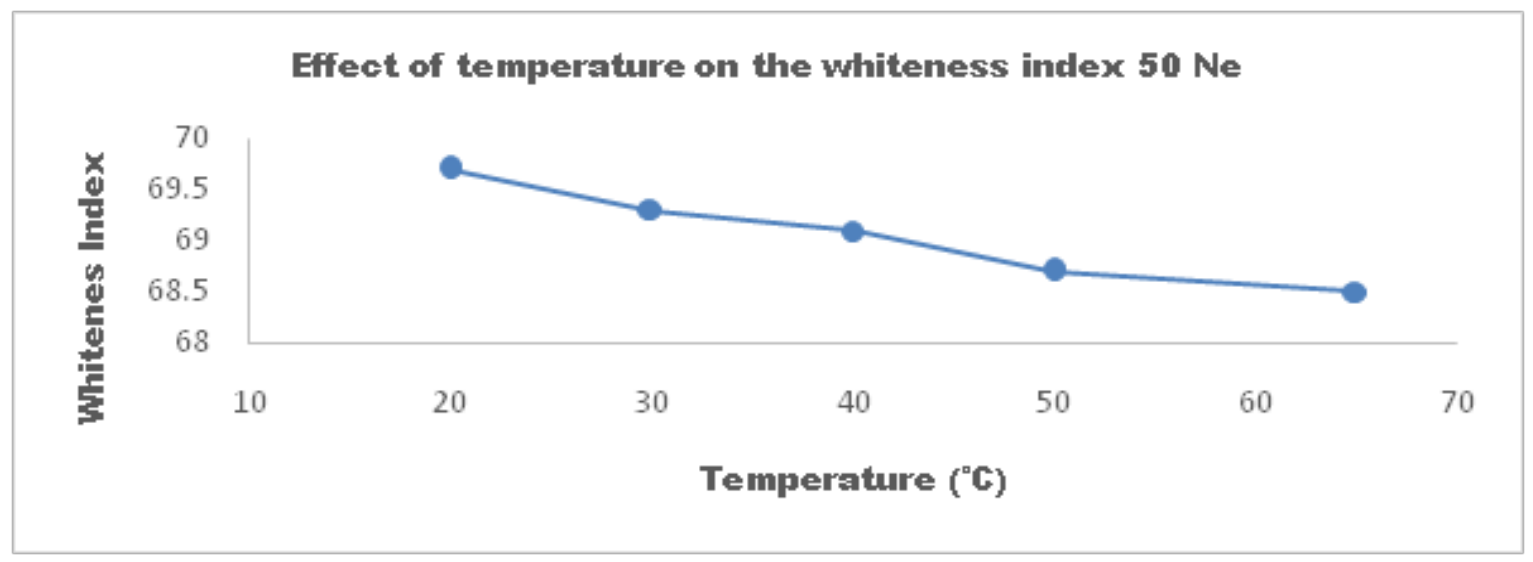

Figure I 4 Effect of temperature and whiteness index $50 \mathrm{Ne}$ on cotton fabric.

Table 7 Effect of temperature and whiteness index with count $32 \mathrm{Ne}$ on cotton fabric

\begin{tabular}{ll}
\hline Temperature $\left({ }^{\circ} \mathbf{C}\right)$ & Whiteness index $(\mathrm{CIE})$ \\
\hline 20 & 69.9 \\
30 & 69.5 \\
40 & 69.2 \\
50 & 69 \\
65 & 68.9 \\
\hline
\end{tabular}

Table 8 Effect of temperature on the whiteness index with count $35 \mathrm{Ne}$

\begin{tabular}{ll}
\hline Temperature $\left({ }^{\circ} \mathbf{C}\right)$ & Whiteness index $(\mathrm{CIE})$ \\
\hline 20 & 79.9 \\
30 & 79.8 \\
40 & 79.4 \\
50 & 79.2 \\
65 & 79 \\
\hline
\end{tabular}

Table 9 Effect of temperature on the whiteness index with count $40 \mathrm{Ne}$

\begin{tabular}{ll}
\hline Temperature $\left({ }^{\circ} \mathbf{C}\right)$ & Whiteness index $(\mathrm{CIE})$ \\
\hline 20 & 69.8 \\
30 & 69.7 \\
40 & 69.2 \\
50 & 69 \\
65 & 68.8
\end{tabular}

Table 10 Effect of temperature on the whiteness index with count $45 \mathrm{Ne}$

\begin{tabular}{ll}
\hline Temperature $\left({ }^{\circ} \mathbf{C}\right)$ & Whiteness index $(\mathrm{CIE})$ \\
\hline 20 & 79.8 \\
30 & 79.5 \\
40 & 79.2 \\
50 & 79 \\
65 & 68.6 \\
\hline
\end{tabular}

Table I I Effect of temperature on the whiteness index with count $50 \mathrm{Ne}$

\begin{tabular}{ll}
\hline Temperature $\left({ }^{\circ} \mathbf{C}\right)$ & Whiteness index $(\mathrm{CIE})$ \\
\hline 20 & 69.7 \\
30 & 69.3 \\
40 & 69.1 \\
50 & 68.7 \\
65 & 68.5
\end{tabular}

\section{Conclusion}

From according the research result it is found that absorbency, increased because while carried out mercerization, the walls of the lumen, i.e., the hollow part of cross section, come closer to such extent that sometimes lumen may even disappear. But the whiteness index of sample is decrease because $\mathrm{NaOH}$ (caustic soda) makes a yellowish layer on the surface of fabric.

i. At low temperature Mercerize is done only on the surface of the fabric but as the temperature is increased the mercerization

ii. The done on the core of the fabric

iii. The absorbency is increased as the temperature is increased

iv. Whiteness index is decreased as the temperature is increased

\section{Acknowledgments}

The Authors wishes to express their heartfelt gratitude to the authorities of GZSCCET bathinda to provide the facilities for conducting the required test in their laboratories. Special thanks are also due to the HOD and staff of Textile Engineering Department of Giani Zail Singh Campus College of engineering and technology, Maharaja Ranjit Singh Punjab Technical University, Bathinda 151001, Punjab (India), without whose help this work would not have been.

\section{Funding}

None.

\section{Conflicts of interest}

Authors have declared no conflicts of interest. 


\section{References}

1. Cardamone JM, Marmer WN. The whitening of textiles. In: Carr CM, editor. Chemistry of the textile industry. Blackie Academic \& Professional, New York: Chapman and Hall; 1995;1(1):46-101.

2. Chastain J, King RC. PHI handbook of X-ray photoelectron spectroscopy, physical electronics. Eden Prairie; 1995.

3. Hage R, Iburg JE, Kerschner J, et al. Efficient manganese catalysts for low-temperature bleaching. Natur.1994;369(1):637-639.

4. Hessler LE, Workman H. Heat induced chemical changes cotton fiber. Textile research journal. 1959;29(6):487-492.

5. Coward FH, Spencer L. The absorption of caustic soda solution by cotton. Journal of textile institute. 1923;14(1):32-45.
6. Perkin SW. Textile coloration and finishing. Durham, North Carolina, USA: Caroline Academic Press; 1996.

7. Mangovska B, Jordanov I. Pad roll bio scouring process for cotton woven fabrics. AATCC Rev. 2006;6(3):33-36.

8. Jordanov B, Mangovska PF. Assessing structural changes in cotton yarns during wet processing, mercerization, and scouring. AATCC Rev. 2007;7(8):56-61.

9. Gamble GR. Effect of elevated temperatures on the chemical properties of cotton fiber pectin. Textile research journal. 2003;79(2):157-160.

10. Hessler LE, Workman H. Heat induced chemical changes cotton fiber. Textile research journal. 1959;29(6):487-492. 